\title{
La puntuación en los textos del Siglo de Oro y en el Quijote
}

\author{
Ignacio Arellano*
}

\section{LA PUNTUACIÓN COMO PROBLEMA DEL EDITOR}

En la tarea de editar un texto no se puede decir que falten dificultades; una de las mayores es la puntuación. Aunque, como se verá, no tenemos un sistema seguro de puntuación, y la subjetividad de cada editor desempeña un papel importante, sí podemos afirmar que hay ciertas soluciones básicas que permiten una lectura más adecuada que otras. Un texto mal puntuado resulta a menudo ininteligible, y propicio a recibir interpretaciones erróneas, o a provocar juicios negativos sobre la habilidad literaria de un escritor al que no se comprende precisamente por no haber sido bien puntuado.

En este terreno los problemas que plantean el Quijote y otros textos cervantinos no son diferentes de los que afectan a los demás textos del Siglo de Oro. Trataré, pues, de algunos aspectos de la puntuación del Quijote en un marco de observaciones generales sobre la puntuación del Siglo de Oro.

Para centrar la discusión posterior propondré algunos ejemplos que me parecen ilustrativos.

Una de las obras que tiene cierto parecido al Quijote en su dificultad de puntuación, por su concepción oralizante y por la complejidad de su estructura (sumamente divagatoria y «espontánea» en este caso) es el Tesoro de la lengua castellana de Covarrubias. En particular, numerosas remisiones y definiciones originales del Tesoro pueden ser confusas sin una puntuación adecuada ${ }^{1}$. En JUVENTUD, por ejemplo, se incluye el comentario «Dezimos jouen en lengua

* GRISO. Universidad de Navarra.

1. Tesoro de la lengua castellana o española, Madrid, Luis Sánchez, 1611. Ver la edición de Arellano y Zafra para todos estos problemas y comentarios más amplios en mi prólogo a esa edición. 
Española antigua, y cortesanamente mancebo». La edición de Riquer modifica la puntuación e imprime: «Dezimos joven, en lengua española antigua y cortesanamente mancebo»; y Maldonado: «Decimos joven, en lengua española antigua, y cortesanamente, mancebo». La de Riquer significa lo contrario de lo que quiere decir Covarrubias (parece que joven es el término actual, y el de la lengua antigua y cortesana mancebo). La de Maldonado sigue siendo confusa. Pero, según Covarrubias, lo antiguo es «joven», lo cortesano es «mancebo», no al revés, como parecería por las puntuaciones de Riquer o Maldonado. El Suplemento al Tesoro lo aclara perfectamente al añadir *JOVEN, que califica de palabra antigua que «vale mancebo». La puntuación mejor en este caso es la original o esta otra algo modificada: «Decimos joven en lengua española antigua y, cortesanamente, mancebo». En la voz SOBERBIA (el original lee: «Algunas vezes sinifica cosa grande, y magnífica, como edificios soberuios. Garcilaso. La sobervia, puerta de los grandes señores.») imprime Riquer: «Algunas vezes sinifica cosa grande y magnífica, como edificios sobervios, Garcilaso. La sobervia, puerta de los grandes señores». Y Maldonado: «Algunas veces significa cosa grande y magnífica, como edificios soberbios, Garcilaso. La soberbia, puerta de los grandes señores.» Ambos editores desconocen el valor del punto como señal introductoria de cita textual ${ }^{2}$, y lo sustituyen por coma, con lo cual se atribuye a Garcilaso lo anterior, en vez de lo que sigue. No se hallará ninguna referencia a los edificios soberbios de Garcilaso, y la puntuación falsea el sentido. Debe imprimirse: "Algunas veces sinifica cosa grande y magnífica, como "edificios soberbios". Garcilaso: "la soberbia puerta/ de los grandes señores"», que son los vv. 45-46 de la segunda égloga.

En los dos ejemplos que acabo de citar tenemos otras pistas para establecer una puntuación más satisfactoria, como son el Suplemento y la misma égloga garcilasiana, pero no siempre contamos con estas ayudas.

Un caso típico ${ }^{3}$ es el de Los peligros de Madrid, de Remiro de Navarra, cuyo estilo calificaba González de Amezúa de descuidado e incorrecto, señalando muchos pasajes ininteligibles o anacolúticos. Como demostró González Ollé lo que necesitaba el texto era una puntuación más adecuada, como evidencian algunos ejemplos ${ }^{4}$.

una sortija de rubíes y otra de diamantes, fondos premios de unas lanzas una sortija de rubíes y otra de diamantes fondos (adjetiva a diamantes), premios de unas lanzas

2. Robles, El culto sevillano, p. 242, critica este uso del punto y reclama para esta función los dos puntos.

3. Ver González Ollé, 1973. Una edición mucho mejor que la de G. de Amezúa es la de S. Arredondo.

4. Primero el texto mal puntuado, luego el correcto. Los dos primeros ejemplos los subsana González Ollé. El tercero pertenece a la ed. de Arredondo, p. 65, y la enmienda que propongo es mía. Una especie de alcahueta recomienda al galán que compre regalos a la dama que pretende, y él se niega: eso es despacharlo, echarlo a puertas. Mejor le parece que la dama se le entre sin más por las suyas... Ver más ejemplos de Quevedo en Arellano, 1990. 
la de Leandro el de habido tres coches; había interpuestos que dificultaron

la de Leandro el de Habido. Tres coches había interpuestos que dificultaron

Eso es echarme a puertas mejores. Pues soy tan amigo de esa dama, se me entre por las mías...

Eso es echarme a puertas. Mejor es, pues soy tan amigo de esa dama, se me entre por las mías...

Una sola coma puede solucionar una fijación textual confusa. Vayamos a un pasaje cervantino del entremés El juez de los divorcios, que siempre se imprime mal puntuado ${ }^{5}$, y que ha dado lugar a distintas propuestas de enmiendas en mi opinión innecesarias. Es la queja de Mariana, en la que esta enumera las fatigas que soporta a causa de su achacoso marido:

el cuydado que tengo de ponerle de noche alta cabecera de la cama, xaraues lenitiuos, porque no se ahogue del pecho

Lázaro Carreter ${ }^{6}$ señaló con precisión las dificultades del pasaje, al comentar las soluciones de diversos editores, y supone una errata:

La errata es evidente porque alta cabecera carece de sentido. Tanto S.B. (Schevill-Bonilla) como Miguel Herrero la han salvado intercalando entre corchetes el artículo la. Con ello el sentido total de la frase mejora algo, pero ahí quedan esos jarabes lenitivos cuya función gramatical es sumamente confusa. De aceptar la inclusión del artículo se produciría un zeugma violentísimo en el que poner habría de jugar dos sentidos muy diferentes: ponerle alta la cabecera de la cama y ponerle jarabes lenitivos. Pero esta última frase constituye otro sinsentido. E. C. (Cotarelo) corrigió con mucha mayor fortuna: «el cuidado que tengo de ponerle de noche la cabecera de la cama jarabes...».

Las ediciones sucesivas del entremés eligen una $\mathrm{u}$ otra de las soluciones que apunta Lázaro, pero el texto original está bien. Únicamente conviene puntuarlo de manera que deje clara la sintaxis, pues alta no se refiere a la cabecera de la cama, sino a noche (noche alta, alta noche, modo adverbial: muy entrada la noche), y cabecera de la cama es un complemento circunstancial de lugar, resto del ablativo local latino sin preposición que se continúa en el español en ciertas estructuras bien conocidas con sustantivos como camino, ribera, orilla, seguidos de una determinación con de y desprovistos de artículo ${ }^{7}$ : pongamos, en suma, una coma después de alta, que delimite esta cláusula absoluta y relacione el adjetivo con el sustantivo correspondiente:

5. Ocho comedias y ocho entremeses, Madrid, Viuda de Alonso Martín, 1615, fol. 221r. Ver Arellano, 1985, artículo que no parecen haber tomado en consideración los editores de los entremeses. Solo Canavaggio trae buena puntuación, aunque en el estado de la cuestión convenía explicarla.

6. Lázaro, 1953.

7. Lapesa, 1964. 
el cuydado que tengo de ponerle de noche alta, cabecera de la cama, xaraues lenitiuos...

Me parece que bastan estos ejemplos para introducir la cuestión. Pero la pregunta es ¿qué puede o qué debe hacer el editor para llegar a un resultado aceptable?, ¿qué guías puede tomar o qué pistas pueden orientarlo?

\section{LA PUNTUACIÓN EN LOS TEXTOS DEL Siglo DE ORO. NOTICIAS TEÓRICAS}

Existe un corpus teórico sobre la puntuación en el Siglo de Oro, que proviene fundamentalmente de tratadistas clásicos antiguos (adaptados o parafraseados por los modernos) y de ciertos impresores que plantean con objetivos algo más prácticos el posible sistema de puntuación. En todos los casos hay que señalar que la distancia entre teoría y práctica real es muy grande.

Fidel Sebastián Mediavilla ${ }^{8}$ ha estudiado detenidamente esta cuestión, con demorados análisis de la puntuación en ediciones de obras fundamentales como La Celestina, el Lazarillo, Guzmán de Alfarache y el propio Quijote, y no queda sino remitir a sus trabajos ${ }^{9}$, de los que tomaré los detalles que ahora me interesan, y usaré como arranque de otras observaciones.

De las teorías de Casiodoro, San Isidoro, y de tratadistas de la Edad Media y el Humanismo, se desprenden varias características: casi todos hablan de coma, cola y periodo, pero les atribuyen dimensiones y funciones diversas. Los signos de puntuación más usuales son el punto (colocado en distintas alturas de la línea para distintas funciones), los dos puntos, la vírgula o raya oblicua, la actual coma, los paréntesis, el calderón, y algún otro. Las funciones se pueden reducir a tres tipos básicos: las orgánicas o rítmicas (la puntuación indica las respiraciones del lector); las estructurales o gramaticales y semánticas (la puntuación marca las unidades de sentido); y las metalingüísticas (marcas de atención sobre determinados vocablos que se quieren individualizar). A estas se añade un tipo de puntuación mecánica en los signos que se colocan en determinadas posiciones: comas sobre todo delante de las conjunciones y otras partículas.

Este panorama es el reflejado en las teorías de los Siglos XVI y XVII, con leves modificaciones. Siempre nos encontramos con un alto grado de indefinición: Alejo Venegas, por ejemplo, admite la vírgula o barra como una especie de coma un poco más pequeña que se puede usar, dice, «cuando la sentencia es muy imperfecta porque no hay verbo y es menester tomar un

8. Sobre todo en su tesis doctoral La puntuación en el Siglo de Oro. Teoría y práctica. Disponible en 〈http://www.tdcat.cbuc.es/TDCat-0720101-093447/〉

9. Ver también Sebastián Mediavilla, 2002, 2003 y su artículo en prensa «La puntuación del Quijote». Agradezco cordialmente al autor el haberme facilitado copias de sus trabajos, sin los cuales no hubiera sido posible esta modesta aproximación mía. 
huelgo insensible que no sea tan vehemente como el de la coma». Aparte de la mezcla de criterios gramaticales-semánticos y de ritmo respiratorio, se advertirá la dificultad de definir el huelgo insensible, el grado de vehemencia de la coma o lo que es un poco más pequeño o más grande...

Nada de extraño tiene que la práctica sea muy irregular. Torquemada en su Manual de escribientes (ca. 1547) se queja del amanuense vizcaíno que trasladó tan mal su texto que ni siquiera en un libro dedicado a las reglas de escribir y puntuar consiguió aplicarlas, pero sobre todo reconoce la discrecionalidad que rige en la materia:

los que escriben y leen el molde van más puntuales [...] que no los que escriben de su propia mano [...] no somos tan curiosos o cuidadosos que nos queramos detener a poner dos puntos en la pausa [...] algunos escriben muy apriesa, y otros descuidados, y otros que no miran en ello, y otros que no se les da nada ni les parece que es falta ${ }^{10}$.

Como indica Sebastián Mediavilla ${ }^{11}$

los mismos términos están cargados de polisemia y las funciones que se les adjudican también son cambiantes. Además, una es la teoría y otra es la práctica que siguen incluso los propios redactores de las normas de puntuación.

Y en suma, podríamos recordar las palabras de Juan de Robles en El culto sevillano ${ }^{12}$ :

no me acuerdo de haber leído libro alguno en latín ni romance (y he leído muchos) que esté a mi parecer perfectamente apuntado...

Pero veamos algunas características de los usos de la puntuación en los textos auriseculares.

\section{LA PRÁCTICA DE LA PUNTUACIÓN. DEL MANUSCRITO AL IMPRESO}

Hay que distinguir en primer lugar los manuscritos de los impresos. Y entre los manuscritos no es lo mismo un borrador autógrafo que una copia en limpio preparada para la imprenta (un «original de imprenta») por un amanuense profesional.

Los manuscritos autógrafos del Siglo de Oro no se preocupan de la puntuación. Es imposible, por tanto, seguir el sistema de puntuación de

10. Cit. en Sebastián Mediavilla, La puntuación en el Siglo de Oro, p. 47.

11. Sebastián Mediavilla, La puntuación en el Siglo de Oro, p. 12.

12. El culto sevillano, p. 241. 
los autógrafos, que dejaban este detalle a la competencia de los cajistas. Los impresos tienen una abundancia de signos notablemente mayor. En los versos 85-110 del autógrafo de El agua mansa ${ }^{13}$ de Calderón solo hay dos comas y un punto; en la edición de Vera Tassis estos versos corresponden exactamente a los 87-112 y llevan 21 comas, 5 puntos, una vez dos puntos, dos acentos.

Resulta significativo que teóricos de la puntuación como Juan de Yziar o Jiménez Patón acaben remitiendo al ejemplo de los buenos impresores como modelo para imitar: es decir, que en la práctica real no se trataba de que el impresor respetase la puntuación de un autógrafo (que no la llevaba); más bien el escribiente podría orientarse a la hora de puntuar siguiendo los modelos de los impresores de prestigio. No tiene sentido, por tanto, en estas circunstancias, plantearse el supuesto grado de fidelidad que un impreso podría mantener respecto a un autorizado modelo autógrafo.

Si el manuscrito era una copia en limpio pudiera ser que esta viniese decentemente puntuada o que careciese de signos, como los borradores o autógrafos originales. En el primer caso el impresor suele seguir muy de cerca el modelo, pero, como señala Sebastián Mediavilla ${ }^{14}$, «si el olfato del cajista detecta pronto que no hay ningún criterio seguro en la puntuación de la copia en limpio, se lanza con la mejor voluntad a intentar arreglarlo», con un resultado casi siempre caótico.

En la práctica esto quiere decir que nunca dispondremos del sistema del autor, entre otras razones porque el autor del Siglo de Oro no tiene sistema.

Un caso revelador lo proporciona de nuevo una serie de autógrafos en limpio de autos sacramentales de Calderón, sin duda preparados para la imprenta por el mismo dramaturgo, que los copia en excelente caligrafía, bien alineados los versos, con claridad y precisión ${ }^{15}$. Pues bien, si examinamos

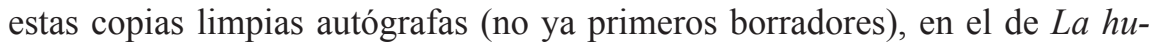
mildad coronada, por ejemplo, se observa la casi total carencia de signos de puntuación y acentuación, no porque Calderón no quisiera ponerlos, sino por que no prestaba en el manuscrito mayor atención a este aspecto.

Las transcripciones modernas se ven obligadas a suplir estos signos, si de verdad desean facilitar la lectura, y si desean constituirse en ediciones críticas. Compárese el autógrafo de La humildad y la transcripción moderna de Sánchez Mariana ${ }^{16}$ :

13. Manejo el facsímil del autógrafo de la Biblioteca del Instituto del Teatro de Barcelona. Para Guárdate del agua mansa, que es como se titula en la edición de Vera Tassis, la ed. facsímil de Varey y Cruickshank, London, Gregg Int., 1973 (Octava parte). Ver la edición de El agua mansa. Guárdate del agua mansa, por I. Arellano y V. García.

14. Sebastián Mediavilla, La puntuación en el Siglo de Oro, p. 67.

15. Me refiero a los dos volúmenes de apógrafos calderonianos custodiados en la Biblioteca Municipal de Madrid, con una veintena de autos copiados en limpio por la mano de don Pedro.

16. La humildad, fols. 4v.-5r. y transcripción moderna, pp. 72-73. Ver mi edición de La humildad coronada, para los problemas de edición y mi propuesta de puntuación del auto. 
Autógrafo:

cedr.

estadme atentos.

que yo sin que os asombre

mi voz puedo deciroslo en su nombre

espin.

que arbol es estranjero

ced.

este que nunca vi, ni verle quiero

o armado espino que Rigor ofreces

mor.

presto porque me ygnoras me aborreces

que tronco es peregrino

ced.

el que a naçer entre nosotros vino

o prudente moral quando me miras

cuerdamente me dudas y me admiras

\section{Transcripción:}

CEDR.

ESPI.

CED.

MOR.

CED.
Estadme atentos, que yo, sin que os asombre mi voz, puedo decíroslo en su nombre.

¿Qué árbol es estranjero éste que nunca vi, ni verle quiero? $¡ \mathrm{O}$ armado Espino, qué rigor ofreces, presto porque me ygnoras me aborreces! ¿Qué tronco es peregrino el que a nacer entre nosotros vino? $¡ O$ prudente moral, quando me miras cuerdamente me dudas y me admiras!

Del punto (por cierto sin mucho sentido) y la coma que había únicamente en el autógrafo, pasa el texto transcrito por Sánchez Mariana (además de quitar el punto sobrante, modificar mayúsculas, etc.) a siete comas, seis acentos, cuatro signos (apertura-cierre) de interrogación, otros cuatro de admiración y un punto: en total se añaden 22 signos en 11 versos.

Como se ha visto, no se trata solamente de la ausencia, sino también de la arbitrariedad de muchos signos de puntuación que sí aparecen en los manuscritos y que es preciso corregir, sin excederse en un «respeto» al original que este no merece.

En la p. 87 de su edición de El pleito matrimonial (Calderón), Engelbert reproduce el texto siguiente:

Pues siendo el alma tan noble, que goza a la edad futura eterna la duracion, porque tiene la segunda de las tres que ay sin principio, sin fin, que es dellas la vna. Solo es duracion de Dios, que sin principio, y fin triunfa, con principio, y fin, que es otra, 


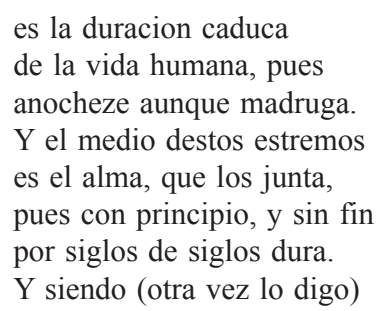

con una puntuación que lo hace ininteligible a menos que el lector reproduzca mentalmente la puntuación aclaradora, que sería más razonable hubiera aportado el editor: es decir, algo como lo siguiente:

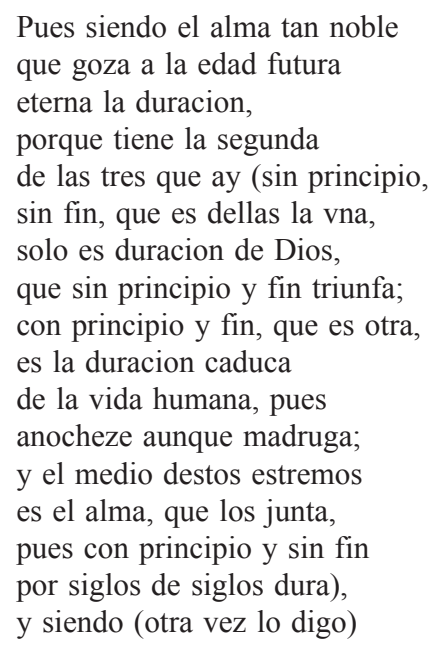

Los ejemplos abundan: en la p. 90, en el pasaje en que habla el Pecado:

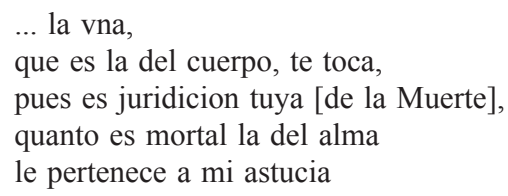

parece atribuir la condición mortal al alma, con una puntuación que deja bastante confuso el sentido del texto, que quedaría mucho más claro si puntuásemos:

... la vna,

que es la del cuerpo, te toca, pues es juridicion tuya, quanto es mortal; la del alma le pertenece a mi astucia 
es decir: 'de las dos partes del hombre, el cuerpo, en tanto es mortal, es jurisdicción de la muerte; el alma, en cambio, es del pecado'. Etc. ${ }^{17}$

Frente a este panorama algunos editores han defendido la conservación del «sistema» del original (como hace Engelbert en el auto calderoniano citado). Uno de los que más ha insistido a propósito de Quevedo es Crosby. Conviene examinar un momento sus argumentaciones.

Aduce Crosby en defensa de lo que llama la puntuación original ${ }^{18}$ la existencia de un sistema coherente de la época capaz de permitir una mejor lectura literaria de los textos:

he optado por evitar la acentuación y la puntuación del siglo $\mathrm{XX}$, porque creo haber observado que existía en el siglo XVII un sistema que hoy da resultados que permiten a un especialista leer estos textos como literatura. En combinación con el deletreo antiguo, la acentuación y la puntuación también antiguas pueden dar lugar a un texto verdaderamente íntegro, ya que su ortografía apoya e ilustra el ritmo de los períodos de la prosa barroca. Por una parte he intentado facilitar la lectura mediante la aplicación consecuente y la extensión ocasional de los criterios de la acentuación de Juguetes; pero por otra, ni he logrado ni he querido eliminar del todo la vacilación tan típica de aquella época, y así la conservo, alguna vez.

Dejando a un lado el hecho de que unas veces se mantiene y otras se modifica la puntuación de Juguetes (de manera que no se advierte cuál sea la coherencia original), toda la argumentación de Crosby es capciosa. Defiende la existencia de un sistema de puntuación en los manuscritos de los Sueños, pero como no hay apenas puntuación en esos manuscritos, recurre a los criterios de la edición de Juguetes de la niñez (esto es, un impreso) para reconstruir ocasionalmente el supuesto sistema original manuscrito, que no existe en ninguna parte. Otras afirmaciones de Crosby son sencillamente erróneas, por ejemplo, la de que:

hoy empleamos la puntuación para indicar las pausas en la lectura y también la construcción sintáctica [...] En cambio, en el siglo XVII la puntuación solo se empleaba para medir la extensión temporal de cada pausa, indicando así al lector el ritmo de los periodos: la coma señalaba una pausa breve, el punto y coma otra más larga, y el punto y los dos puntos la pausa más larga de todas ${ }^{19}$

Ya se ha visto que esto no era así, y que la puntuación tiene varias funciones. El elenco de signos que menciona Crosby tampoco responde a la realidad: el punto y coma, por ejemplo, no existe en toda la Primera parte del Quijote. Crosby llega al extremo de rehusar aplicar ciertos signos que no se usaban

17. Otros casos análogos en la ed. de Engelbert, pp. 97, vv. 296-298; 101, vv. 372-375; 106-107, vv. $477-78$...

18. Ver su edición de Política de Dios, o Crosby, 1991 (la cita de arriba en este trabajo, p. 137). Pero no existe la tal puntuación original. Es solo una hipótesis ideal de Crosby.

19. Ed. de Quevedo, Sueños, I, pp. 112-113. 
en la época, como las comillas o guiones para marcar los diálogos, porque «su presencia daría lugar a un resultado híbrido y anómalo». Esto es elevar una carencia de la imprenta aurisecular a criterio científico: precisamente los textos dialogados son los que mayores dificultades plantean al puntuador, y las comillas y guiones mejoran extraordinariamente la claridad de una edición. Crosby se obliga a imprimir cosas como la siguiente ${ }^{20}$ :

preguntandoselo a vn demonio, me dixo: Èstos son los de: Dios es piadosso, a quien condenò la misericordia de Dios. Dios sea comigo! dixe al punto, Pues còmo puede ser que la Misericordia condene, siendo esso de la justicia? Vos hablais como diablo. Y vos (dixo el diablo) como ignorant: pues no sabueis que la metad de los que estàn aqui se condenan por la misericordia de Dios?

Mi propuesta $\mathrm{es}^{21}$ :

preguntándoselo a un demonio, me dijo:

-Estos son los de «Dios es piadoso, Dios sea conmigo».

Dije al punto:

- ¿Pues cómo puede ser que la misericordia condene, siendo eso de la justicia? Vos habláis como diablo.

- Y vos — dijo el diablo - como ignorante; ¿pues no sabéis que la mitad de los que están aquí se condenan por la misericordia de Dios?

No creo que quisiera Quevedo que su texto se leyera de carrerilla, por más que la imprenta del XVII no marque estos signos auxiliares.

Crosby, por lo demás, quita a veces la coma ante conjunción para favorecer «el ritmo», pero en la p. 239, por ejemplo ${ }^{22}$, imprime:

has visto al Otro en blanco, y que no tiene nada escrito, y que no dize nada ni lo ha de dezir ni lo ha dicho: y que desmiente desde aqui a quantos me citan y achacan lo que no saben, pues soy el Autor de los Idiotas y el texto de los Ignorantes. Y has de aduertir...

Si unas veces elimina la coma delante de la copulativa, en otras, como se ve en el pasaje citado, la mantiene, o mantiene dos puntos, o un punto: en cuatro líneas de texto tenemos coma delante de conjunción, ausencia de coma en la misma posición, punto y dos puntos... Llamar a estas cuatro soluciones diferentes «sistema» es muy optimista.

Pero a fin de cuentas Crosby maneja copias no autógrafas y textos impresos de garantía variada.

Alfonso Rey ha intentado esa «fidelidad», apoyándose en el caso concreto de Quevedo, en el texto autógrafo de Virtud militante, partiendo de la pun-

20. Ed. de Quevedo, Sueños, I, p. 173.

21. En mi ed. de Los Sueños, de Cátedra, p. 206.

22. No hace al caso acumular ejemplos, que serían innumerables. 
tuación del mismo Quevedo ${ }^{23}$. Pues bien, esa puntuación original observa la misma arbitrariedad de la que vengo hablando. No es ciertamente caótica, pero mucho menos se puede llamar sistemática. ¿Cómo explicar, por ejemplo, el punto que separa el sustantivo de su adjetivo calificador en la p. 74, línea 5: antídoto. Eficaz? Se pueden acumular series enumerativas con todos sus elementos separados por comas (página: línea: 81:162-4; 82:170-71; 92:480$82 ; 96: 70-71 ; 96: 70-71 \ldots$ y series idénticas con algunos miembros sin comas separativas (73:3-4; 74:12-13; 81:145; 101:225-26...). A veces Rey las añade para completar lo que es sin duda la práctica general. Tampoco son raros los casos en que la puntuación del autógrafo se opone a la disposición retórica (que se supone debiera corresponder a la rítmica). En la p. 76 (líneas 22-23) el esquema del paralelismo anafórico responde a una construcción progresivamente ramificada:

[1] Aquí está la invidia difinida,

[2] aquí exemplificada,

[3] aquí [3.1] se descubre su intento

[3.2] se nombran sus armas.

[3.3] Se dan sus señas.

La puntuación (comas, ausencia de comas, punto) no corresponde a ninguna hipótesis rítmica y contradice la organización retórica del texto. En la p. 78 (líneas 56-57) hay un esquema paralelístico de tres miembros, cada uno de ellos formado por una pareja antitética. Los tres miembros básicos se separan siempre con puntos; las parejas que los forman se separan con comas en los dos primeros, pero no en el tercero:

No solo se inuidian los bienes, sino los males. No solo las honras, sino las afrentas. No solo la prosperidad sino la miseria.

Y veáse, en fin, la puntuación del pasaje siguiente (p. 81, líneas 151-54) constituido por una enumeración anafórica con tendencia a la ley de miembros crecientes, cuyos elementos se separan o no, con comas o puntos según una coherencia para mí indescifrable ${ }^{24}$ :

éste no be lo que mira éste no güele en la suavidad de la adulaçión el humo del engaño éste, en la golosina de la lisonxa no gusta el azíbar, del peligro. Éste en lo blando de la mentira no toca lo áspero de la perdizión.

23. Rey afirma que «muy poco se sabe de la puntuación de Quevedo» (p. 61), supone en el poeta un cuidado por la puntuación evidente en algunos comentarios suyos (ver pp. 62-67; creo que Rey concede demasiada importancia a detalles poco seguros), y opta en fin por respetar la puntuación del autógrafo, con algunas adaptaciones. Ver también Rey, 1990. He comentado estos asuntos en Arellano, 1986.

24. Ver, entre múltiples ejemplos, pp. 79 (líneas 94-95), 82 (líneas 77-78, 185-95), y otros diversos en pp. 99, 113-14... 


\section{LA PUNTUACIÓN DEL QUIJOTE}

Pero vayamos, tras este rodeo, al Quijote, para examinar someramente el panorama de la puntuación. En la edición del Instituto Cervantes afirma Francisco Rico que «la materia más delicada con que debe enfrentarse un editor del Quijote tal vez sea la puntuación $»^{25}$, y que «desazona particularmente comprobar hasta que extremo construcciones y estilemas continuos en el Quijote toleran diversas soluciones de puntuación».

Se comprende, en la ausencia de un sistema, que un editor se encuentre con tantos problemas enfrentado a la tarea de puntuar el Quijote, que acumula a su extensión y variedad de registros y modelos lingüísticos una condición de lengua hablada que resulta, además, muy difícil de reflejar con cualquier sistema de puntuación, aunque lo hubiera.

Los autógrafos cervantinos carecen, como todos los de su tiempo, de puntuación, como subrayó Romera Navarro ${ }^{26}$ :

no traen un solo caso de coma, de punto y coma, de dos puntos [...] ni el acento, las diéresis o el guión en la división de una palabra al fin de renglón... Jamás aparecen el paréntesis, el subrayado, ni otro signo ortográfico auxiliar, excepto el punto, y este rarísimamente.

La posible reconstrucción por parte del editor moderno de la puntuación cervantina solo dispone de los testimonios impresos de las primeras ediciones y otras sucesivas, algunas verosímilmente revisadas (de modo parcial seguramente) por el propio Cervantes. Para entender el grado de «autenticidad» de esa puntuación conviene recordar el proceso de la imprenta que afectó al Quijote y examinar la puntuación real de las primeras ediciones.

Rico ${ }^{27}$ ha precisado el mecanismo de impresión del Quijote, y me limitaré a apuntar ahora que los componedores de la Primera Parte (al menos tres) partirían de una copia en limpio u original de imprenta ${ }^{28}$ (revisado por un corrector) sobre la que calcularían los trozos de texto que debían componer en cada forma o cara del pliego, para que al plegarlo y encuadernarlo la secuencia de lectura fuese la correcta. Por más regular que fuese esta copia siempre hay un margen de error en la cuenta; cuando es pequeño se puede subsanar echando mano, precisamente de la puntuación: aumentándola o suprimiéndola se gana o ahorra espacio en una plana. Cada etapa del proceso puede acumular así irregularidades en la puntuación. Lo dicho vale para la Primera Parte impresa a final de 1604 (la conocida como príncipe de 1605). Una nueva edición de 1605 y sobre todo una tercera de 1608 en la misma imprenta de Juan de la Cuesta, son ediciones corregidas, seguramente por

25. Edición citada del Quijote, vol. II (complementario), pp. 692-694.

26. Romera Navarro, 1954, p. 13. Ver Brown y Blanco-Arnejo, 1989.

27. Edición citada, capítulo «Historia del texto», pp. CXCII y ss. Ver también Rico, 2004.

28. Para lo referente a las copias en limpio ver Garza, 2000. 
Cervantes, sobre el modelo de la primera (1604), que muestran cambios de puntuación, entre otros.

Sea como fuere conocemos muy bien la puntuación del Quijote que salió al fin de las prensas, por el exhaustivo trabajo de Sebastián Mediavilla, quien ha descrito minuciosamente la puntuación de los Quijotes de 1605 y 1615, y que me permite extraer unas pocas observaciones ejemplares, remitiendo a su hercúlea tarea para mayores detalles.

En resumen puede decirse que la puntuación en las primeras ediciones del Quijote no es exactamente caótica. Hay usos de valor absoluto (punto al final de las oraciones, o signos de interrogación), y otros más relativos. Hereda prácticas muy antiguas como la presencia de coma delante de determinadas conjunciones (pero no sistemática delante de la conjunción que, o del pronombre relativo), y separa a menudo mediante coma a las proposiciones subordinadas sustantivas. El punto y coma no se usa en 1605; en cambio es abundante el uso de dos puntos. Apenas hay punto y aparte, porque el texto no se distribuye en párrafos. Abundan los paréntesis y el signo interrogativo de cierre se aplica a interrogativas directas e indirectas. Sebastián Mediavilla ha establecido las reglas generales del modo siguiente:

1. Punto o dos puntos o punto y coma entre oración y oración.

2. Punto, dos puntos o coma para dar entrada a una frase en estilo directo.

3. Separación de oraciones yuxtapuestas con coma, punto y coma o dos puntos.

4. Separación por medio de coma (o puntuación más fuerte) de las oraciones copulativas, disyuntivas, adversativas, causales, concesivas y condicionales.

5. No hay criterio uniforme respecto a la puntuación en oraciones consecutivas, finales y comparativas.

6. Las oraciones relativas se tratan de distinto modo: las explicativas se suelen acotar por comas; las especificativas van sin comas. Hay excepciones.

Hay muchas erratas e inconsistencias, no debidas a Cervantes (que no puntuaba) sino a los amanuenses, correctores o cajistas. Explica Sebastián Mediavilla $^{29}$ :

ni todas las comas están donde deberían estar, ni todos los puntos o dos puntos. Las anomalías - por defecto o por exceso- en la edición princeps son muchas. Y como consecuencia de ello, la deturpación del texto, frecuente. Los pasajes en los que se aprecia una mayor densidad de errores de puntuación, y una consiguiente corrupción del texto, se encuentran en los diálogos: faltas o sobras de comas, ausencias de signos de interrogación o su inclusión en lugar inoportuno, producen un agravio al autor y un considerable desconcierto al lector.

29. Sebastián Mediavilla, La puntuación en el Siglo de Oro, p. 488, y su artículo «La puntuación del Quijote». 
Ya Rico había señalado en la «Historia del texto» preliminar de la edición del Instituto Cervantes que una de las peores lacras de la primera edición del Quijote era la «formidable cantidad de erratas». Sebastián Mediavilla recoge una buena cantidad de erratas e inconsistencias. Valgan unos pocos ejemplos solamente de la Segunda parte de 1615:

sobre la sangre y pecho de don Vicente, se quedô desmayada, y a el le tomô un mortal parasismo, confuso estava Roque, y no sabia que hazerse (232r., lín. 20) $)^{30}$

y a esto llaman pobreza de espiritu: pero tu segunda pobreza (que eres de la que yo hablo)... (166v., lín.9) ${ }^{31}$

anteviendo que yo, avia de quedar vencedor $(54 \mathrm{v} ., \text { lín. } 18)^{32}$

Fue condicion de los combatientes, que si don Quixote vencia su contrario, se avia de casar con la hija de doña Rodriguez (214r., lín. 14) $)^{33}$

Podemos considerar, pues, un sistema, pero no lo podemos ver aplicado en las ediciones primeras. El modelo puede ser útil, pero con una utilidad no sistemática, sino auxiliar. Y esto no solo para el Quijote, sino para la inmensa mayoría de los textos auriseculares. Es bien significativo que la utilidad más indiscutible del análisis de la puntuación sea la de permitir filiaciones en los estemas de distintas ediciones que muestran coincidencias o divergencias en este aspecto, como han mostrado Blecua para el Lazarillo o Sebastián Mediavilla para la Celestina y el Lazarillo ${ }^{34}$. Otra utilidad es la de permitir distinguir los diversos cajistas que han compuesto cada parte de un libro: se advierte que estos cajistas suelen tener su «sistema» o manierismos propios, pero precisamente la inexistencia de un sistema general permite las variaciones. Y además ${ }^{35}$ muchos de los criterios de los correctores y componedores son mecánicos o inestables.

La puntuación de las primeras ediciones (y de todas las posteriores) puede enseñarnos muchas cosas y ayudarnos a fijar el texto cervantino, pero no es una guía estrictamente práctica. Dicho de otro modo: es poco relevante en cuanto sistema; es valiosa orientación para pasajes concretos. En este sentido no parece aceptable la postura de Flores ${ }^{36}$ y otros defensores del mantenimiento ajustado a las ediciones príncipes «sin tomar en cuenta ninguna otra edición de la obra, ni de ninguna otra obra de Cervantes, ni de ningún otro elemento ajeno a Cervantes en ningún periodo en la historia de la lengua española».

30. Entre las palabras que pongo en cursiva debe ir punto separativo de dos oraciones.

31. Requiere acentuar y separar con coma el vocativo: «tú, segunda pobreza».

32. Separa sujeto y verbo con coma.

33. Si don Quijote vence a su contrario es este y no don Quijote el que se ha de casar: «si don Quijote vencía, su contrario [sujeto] se había de casar con la hija...».

34. Sebastián Mediavilla, La puntuación en el Siglo de Oro, capítulos dedicados a estas obras, y del mismo autor su artículo de 2003. Para el Lazarillo ver la ed. de Blecua, 1972 y sus observaciones sobre la puntuación.

35. Rico, ed. Quijote, vol. II, p. 692.

36. Flores, 1988. 
Pero es que la puntuación de los Quijotes primeros tiene, sin duda, mucho de ajeno a Cervantes...

Si no conviene ceñirse a la puntuación de las ediciones primeras, ¿cuál es la conveniente? Todos los editores modernos se acogen a la llamada «puntuación moderna», pero ahí tenemos un nuevo problema, porque la puntuación moderna tampoco obedece a un sistema bien definido.

Aunque Sebastián Mediavilla, aceptando afirmaciones de José Polo, cree en la objetividad de la puntuación moderna y califica de prejuicio a la idea de la subjetividad, más en lo cierto se halla Rico ${ }^{37}$ cuando señala que el problema de puntuar el Quijote «no está (o no solo ni directamente) en la ausencia o arbitrariedad de la puntuación en Cervantes o en la princeps, sino en el asistematismo de la que modernamente se emplea en español». La puntuación moderna tiene mucho de subjetivo, y de elecciones personales, a menudo de poca trascendencia significativa.

Problema diferente es la poca capacidad de la puntuación (antigua y moderna) para expresar muchos usos lingüísticos de Cervantes. Rico trae, entre otros, el ejemplo del comienzo del capítulo 6 de la I Parte:

Pidió las llaves a la sobrina del aposento, donde estaban los libros, autores del daño, y ella se las dio (18r)

¿Cómo puntuar esto? Los editores han probado soluciones diversas para todos los gustos:

Pidió las llaves a la sobrina, del aposento donde estaban los libros autores del daño, y ella se las dio (Clemencín)

Pidió las llaves a la sobrina del aposento donde estaban los libros autores del daño, y ella se las dio (Gaos, Rico, Alberto Blecua)

Pidió las llaves, a la sobrina, del aposento donde estaban los libros, autores del daño, y ella se las dio (Allen, Sevilla Arroyo y Rey Hazas)

Pidió las llaves, a la sobrina, del aposento donde estaban los libros autores del daño, y ella se las dio (Riquer, Avalle Arce, Pedraza)

Pidió las llaves, a la sobrina del aposento donde estaban los libros autores del daño, y ella se las dio (Murillo)

Elija el discreto lector la que más le satisfaga (la de Murillo no es buena).

\section{FINAL}

De la consideración atenta de las puntuaciones antiguas, cuando sirvan de algo (no siempre) y del análisis meticuloso del texto podría establecerse una puntuación adecuada de las obras cervantinas, que no sería la única posible.

37. Rico, ed. Quijote, vol. II, p. 693. 
Lo que se debe perseguir, a mi juicio, es la coherencia general de los criterios aplicados, que no excluye un grado de flexibilidad bastante notable.

Precisamente la indefinición y asistematicidad de la puntuación española moderna tiene una consecuencia positiva, pues, como propone $\operatorname{Rico}^{38}$ :

también se nos antoja que en la enfermedad está la medicina. La inmensa libertad de uso que acompaña a ese capítulo de la ortografía española impone y a la vez permite ir respondiendo a las conveniencias de la obra o del lector con remedios diversos, sin buscar una regularidad vedada tanto por la índole del lenguaje cervantino como por las circunstancias de nuestra puntuación.

\section{BIBLIOGRAFÍA}

Arellano, I., «Un pasaje cervantino dificultoso en El juez de los divorcios», Romance Notes, XXVI, 1, 1985, pp. 1-5.

Arellano, I., Reseña a La virtud militante, de Quevedo, ed. A. Rey, Criticón, 35, 1986, 135-140.

ARELlANO, I., «Varias notas a lugares quevedianos. Fijación textual y crítica filológica», en La edición de textos (Actas del I Congreso de la Asociación Internacional Siglo de Oro), London, Tamesis books, 1990, pp. 123-131.

BlecuA, A., ed., La vida de Lazarillo de Tormes, Madrid, Castalia, 1972.

Brown, K. y Blanco-Arnejo, M. D., «Dos documentos inéditos cervantinos», Cervantes, 9.2, 1989, pp. 5-20.

CAlderón, P., El agua mansa. Guárdate del agua mansa, ed. de I. Arellano y V. García, Kassel, Reichenberger, 1989.

CAlderón, P., El pleito matrimonial del cuerpo y el alma, ed. M. Engelbert, Hamburg, Ludwig \& Appel, 1969.

CAlderón, P., Guárdate del agua mansa, edición de Vera Tassis, en Calderón, Comedias. A facsimile edition prepared by D. W. Cruickshank and J. E. Varey, London, Gregg Int. and Tamesis books, 1973.

CAlderón, P., La humildad coronada, autógrafo en la Biblioteca Nacional de Madrid, Ms. 14849.

CAlDERÓn, P., La humildad coronada, ed. I. Arellano, Kassel, Reichenberger, 2002.

CALDERÓN, P., La humildad coronada, facsímil del autógrafo con transcripción paleográfica de M. Sánchez Mariana, Madrid, Espasa Calpe, 1980.

Cervantes, M. DE, Don Quijote de la Mancha, ed. D. Clemencín, Valencia, Ortells, 1980.

Cervantes, M. DE, Don Quijote de la Mancha, ed. dir. por F. Rico, Barcelona, Instituto Cervantes-Crítica, 1998, 2 vols.

Cervantes, M. De, Don Quijote de la Mancha, ed. A. Blecua y A. Pozo, Madrid, Espasa Calpe, 1998.

Cervantes, M. De, Don Quijote de la Mancha, ed. F. Pedraza, Madrid, Algaba, 2004.

Cervantes, M. DE, Don Quijote de la Mancha, ed. F. Sevilla y A. Rey Hazas, Madrid, Alianza, 1996.

Cervantes, M. DE, Don Quijote de la Mancha, ed. J. B. Avalle Arce, Madrid, Alhambra, 1979.

38. Rico, ed. Quijote, vol. II, p. 697. 
Cervantes, M. De, Don Quijote de la Mancha, ed. J. J. Allen, Madrid, Cátedra, 1980.

Cervantes, M. DE, Don Quijote de la Mancha, ed. M. de Riquer, Barcelona, Planeta, 1992.

Cervantes, M. DE, Don Quijote de la Mancha, ed. V. Gaos, Madrid, Gredos, 1987.

Cervantes, M. DE, Don Quijote de la Mancha, ed. L. A. Murillo, Madrid, Castalia, 1984.

Cervantes, M. DE, Entremeses, ed. J. Canavaggio, Madrid, Taurus, 1981.

CERVAntes, M. DE, Ocho comedias y ocho entremeses, Madrid, Viuda de Alonso Martín, 1615.

CovarRuBias, S. DE, Tesoro de la lengua castellana o española, según la impresión de 1611, con las adiciones de Padre Benito Remigio Noydens publicada en la de Madrid, 1674, ed. M. de Riquer, Barcelona, S. A. Horta, 1943.

Covarrubias, S. DE, Tesoro de la lengua castellana o española, ed. F. C. R. Maldonado, revisada por M. Camarero, Madrid, Castalia, 1995.

CovarRuBias, S. DE, Tesoro de la lengua castellana o española, ed. integral e ilustrada de I. Arellano y R. Zafra, Madrid/Pamplona, Iberoamericana/Universidad de Navarra/ RAE/Centro para la Edición de los Clásicos Españoles, 2006.

Covarrubias, S. de, Tesoro de la lengua castellana o española, Madrid, Luis Sánchez, 1611.

Crosby, J., «Una transcripción de los manuscritos de los Sueños de Quevedo», en Crítica textual y anotación filológica en obras del Siglo de Oro (Actas del II Seminario Internacional de Edición y Anotación de textos del Siglo de Oro), ed. I. Arellano y J. Cañedo, Madrid, Castalia, 1991, pp. 135-141.

GARZA, S., «La cuenta del original», en Imprenta y crítica textual en el Siglo de Oro, ed. F. Rico, Valladolid, Centro para la Edición de los Clásicos españoles, 2000, pp. 65-95.

GonZÁLez Ollé, F., «Conceptismo y crítica textual», en Studia Iberica. Festschrift für Hans Flasche, Bern-Munchen, Francke, 1973, pp. 189-196.

LAPESA, R., «Los casos latinos: restos sintácticos y sustitutos en español», Boletín de la Real Academia Española, 44, 1964, pp. 57-105.

LÁZARO, F., «Notas sobre el texto de dos entremeses cervantinos», Anales cervantinos, 3, 1953, pp. 340-348.

Quevedo, F. de, Los sueños, ed. I. Arellano, Madrid, Cátedra, 1991.

Quevedo, F. de, Política de Dios, gobierno de Cristo y tiranía de Satanás, ed. J. Crosby, Madrid, Castalia, 1966.

Quevedo, F. de, Sueños y discursos, ed. J. Crosby, Madrid, Castalia, 1993, 2 vols.

Quevedo, F. de, Virtud militante, ed. A. Rey, Santiago, Universidad, 1985.

Remiro De Navarra, B., Los peligros de Madrid, ed. A. González de Amezúa, Madrid, Sociedad de Bibliófilos Españoles, 1956.

Remiro de Navarra, B., Los peligros de Madrid, ed. S. Arredondo, Madrid, Castalia, 1996.

REY, A., «Notas sobre la puntuación en Quevedo», en La edición de textos (Actas del I Congreso de la Asociación Internacional Siglo de Oro), London, Tamesis books, 1990, pp. 385-392.

Rico, F., En torno al error. Copistas, tipógrafos, filologías, Madrid, Centro para la Edición de los Clásicos Españoles, 2004.

Robles, J. DE, El culto sevillano, ed. A. Gómez Camacho, Sevilla, Universidad, 1992.

Romera Navarro, M., Autógrafos cervantinos, Austin, University of Texas Press, 1954.

Sebastián Mediavilla, F., «Las primeras ediciones de La Celestina y su puntuación», Boletín de la Real Academia Española, 83, 2003, pp. 113-135. 
Sebastián Mediavilla, F., La puntuación en el Siglo de Oro. Teoría y práctica, Tesis doctoral de la Universidad Autónoma de Barcelona, 2001. Disponible en 〈http://www. tdcat.cbuc.es/TDCat-0720101-093447/>

Sebastián MediaVILla, F., La puntuación en los siglos XVI y XVII, Barcelona, Servicio de Publicaciones de la Universidad Autónoma, 2002.

Sebastián Mediavilla, F., «La puntuación del Quijote», en prensa.

Recibido: 1 de diciembre de 2009

Aceptado: 9 de junio de 2010

\title{
Resumen
}

El artículo trata de las prácticas de puntuación en los textos del Siglo de Oro, y en particular en el Quijote. Examina la discrepancia entre las teorías y la práctica de los impresores, las características de la puntuación en manuscritos, y la falta de sistema general que se debe en parte a la inexistencia de un sistema único en español. Se integran en el comentario numerosos ejemplos de textos auriseculares y del Quijote.

Palabras clave: Puntuación. Manuscritos. Impresos. Quijote.

Title: Punctuation in the texts of the Golden Age and in Don Quijote

\begin{abstract}
This article examines the punctuation in Golden Age texts, in particular in Don Quixote. The author analyzes the discrepancies between theory and practice of the printers, the features of the punctuation in manuscripts, and the absence of a general system, due in part to the absence of a unique and precise system in Spanish. The article provides numerous examples of Golden Age text and of the Quixote.
\end{abstract}

Key words: Punctuation. Manuscripts. Prints. Don Quixote. 